\title{
A GESTÃO DO CORPO NEGRO NO BRASIL: DA DEMOCRACIA RACIAL AO GENOCÍDIO
}

\author{
Vinícius de Souza Assumpção ${ }^{1}$
}

\section{RESUMO:}

Os levantamentos sobre encarceramento, tortura e violência no Brasil revelam a existência de uma política de gestão da morte que atinge especialmente os negros e negras do país. A segregação racial antecedeu a Abolição da Escravatura e permaneceu após o ato formal de 1888 , tendo assumido novas roupagens, às vezes camufladas e reduzidas ao conflito de classes, outras silenciadas sob o mito da democracia racial. Da criminologia às políticas institucionais, a identidade negra foi construída como uma massa de vidas descartáveis, passível de contenção nas prisões e extermínio.

Palavras-chave: Racismo; Sistema Penal; Genocídio; Criminologia Crítica

\section{BLACK BODY'S MANAGEMENT IN BRAZIL: FROM RACIAL DEMOCRACY TO GENOCIDE}

\begin{abstract}
:
The surveys of imprisonment, torture and violence in Brazil reveal the existence of a death management policy affecting mainly black men and women. Racial segregation preceded the Abolition of Slavery and remained after the formal act of 1888, having assumed new attires, sometimes camouflaged and reduced to class conflict, others silenced under the myth of racial democracy. From criminology to institutional policies, black identity was constructed as a mass of disposable lives, liable to containment in prisons and extermination.
\end{abstract}

Keywords: Racism; Criminal System; Genocide; Critical Criminology

\section{INTRODUÇÃO}

Apesar do transcurso de mais de um século de superação formal da abolição da escravidão, o Brasil convive com elevadas taxas de encarceramento, tortura e assassinato do povo negro, o que conduz à investigação da formação da identidade negra no país e da consistência do recorrente discurso da existência de uma "democracia racial". O aprofundamento do estudo das raízes históricas e antropológicas brasileiras revela que o rompimento com a estrutura formal escravocrata não se traduziu em emancipação, mas em sofisticação do aprisionamento (real e metafórico), lapidado na cristalização de um padrão identitário ariano, classista e sexista.

\footnotetext{
${ }^{1}$ Mestre em Direito Público pela Universidade Federal da Bahia, Especialista em Direito do Estado pelo JusPodivm, Advogado Criminalista. Bahia (Brasil). E-mail: viniciusassumpçao@ outlook.com
} 
A consolidação do racismo recebeu expressiva contribuição da criminologia, que tem sua gênese marcada pela associação lombrosiana de determinadas raças à inferioridade e propensão (quando não determinismo) à criminalidade. O estudo do crime enquanto fenômeno evoluiu para incorporar as noções de vulnerabilidade e seletividade, adquirindo-se a consciência de que o delito não passa de uma etiqueta aposta a comportamentos indesejados, entretanto a ruptura paradigmática não se fez acompanhar de medidas efetivas viabilizadoras do abandono do padrão de encarceramento, tortura e extermínio do povo negro.

O estudo objetiva perquirir as bases da desumanização do povo negro, através da pesquisa das referências bibliográficas que se reportam ao momento histórico imediatamente pré-abolição e àquelas que sucedem esse marco. Com o auxílio da antropologia, sociologia e psicologia (especialmente da neurociência), intentou-se identificar quais mecanismos tornam possível a aceitação do racismo na sociedade para, à luz da criminologia crítica, analisar os relatórios atualizados do aprisionamento, da prática de tortura e do genocídio do povo negro no Brasil.

\section{O PROCESSO DE ABOLIÇÃO DA ESCRAVIDÃO E A CONFORMAÇÃo DA IDENTIDADE NEGRA NO BRASIL}

O dia 13 de maio de 1888 é o marco simbólico da (tardia) Abolição da Escravidão no Brasil. O evento histórico foi precedido pela promulgação da Lei Eusébio de Queirós (1850), da Lei Rio Branco ou do Ventre Livre (1871) e da Lei Saraiva-Cotegipe ou dos Sexagenários (1885), consideradas etapas para a edição da Lei Áurea, embora cada uma trouxesse consigo suas limitações e eventuais inviabilidades práticas ${ }^{2}$. Esse conjunto de diplomas configura o plano meramente formal de rompimento com as estruturas escravocratas, sendo certo que circunstâncias antecedentes e posteriores revelam as dimensões de exclusão e tentativa de embranquecimento do povo negro, operadas em planos simultâneos.

$\mathrm{O}$ contexto nacional pré-abolição revelava estruturas brancas, paternalistas e estratificadas suficientemente sedimentadas para não sofrerem risco de corrosão com o ato da princesa Isabel no final da década de 80. O abandono da escravidão formal é, essencialmente, "um negócio de brancos", forjado nas controvérsias e antagonismos dos grupos dominantes na certeza de que não se alteraria o status quo (IANNI, 1978, p. 36). Aliás, a proporção entre

\footnotetext{
${ }^{2}$ Segundo Mattoso, a maioria das liberdades era feita a título oneroso ou submetidas a cláusulas restritivas, servindo ao interesse dos proprietários. Como exemplo desse cenário, a autora pontua que, até 1865, a alforria concedida ao escravo poderia ser revogada pelo seu proprietário (2003, p. 176-180).
} 
pessoas livres das "raças" "parda", "preta" ou "cabocla" e aquelas escravizadas já anunciava que a liberdade não havia modificado a hegemonia do poder vigente: a cada 3 (três) pessoas “de cor" livres havia 1 (uma) escravizada, segundo o primeiro recenseamento do país, realizado em $1872^{3}$.

Segundo Thomas Skidmore (1976) ainda na vigência da escravidão, os "homens livres de cor" alcançaram uma certa mobilidade social (sobretudo os mais "claros"), criando as bases para o nefasto "mito da democracia racial". Enquanto nos tribunais do sul dos Estados Unidos vigia a One-Drop Rule (GEULEN, 2010, p.115), símbolo de um sistema birracial rígido $^{5-6}$, no Brasil se notava nítida multirracialidade, marcada pela existência de uma "categoria mediaria (os chamados mulatos ou mestiços)" (SKIDMORE, 1976, p. 54). A multirracialidade era nota característica, mas não sinônimo de aceitação social. É nesse sentido que Ramos afirma que os negros e negras libertos seguiram com sua alma "presa aos grilhões do seu complexo de inferioridade coletivo" (1940, p. 12).

Os mecanismos genocidas, atualmente aprimorados, são engendrados desde então, com estratégias de embranquecimento como estupros sistemáticos da mulher negra pelo homem branco, a originar pessoas de "sangue misto" ("mulato, pardo, moreno, pardo-vasco, homem-de-côr, fusco") (NASCIMENTO, 1978. p. 69). Segundo Fernandes, no estado de São Paulo o processo de "branquificação" foi resultado do grande fluxo de imigrantes estrangeiros (brancos) e das condições precárias de vida dos negros e negras, da qual resultou aumento do número de óbitos e redução dos nascimentos ${ }^{7}$. Em cenário como esse, a miscigenação possuiu "uma significação claramente exterminadora, diluindo-o e fazendo-o desaparecer, através dos descendentes mulatos nos contingentes mestiços da população global” (2008, p. 134). Na cidade de Salvador, Bahia, o contexto de miscigenação teria sido mais abrangente, porém igualmente marcado pela tentativa de "limpar o sangue" do povo negro, embora se reconheça na literatura maior inclusão das pessoas miscigenadas - como se conclui, por exemplo, a partir

\footnotetext{
${ }^{3}$ Ainda segundo o Censo, eram, ao todo, 4.638.328 pessoas livres contra 1.510.806 pessoas em regime de escravidão (IBGE, 1874?).

${ }^{4}$ Segundo essa regra, uma gota de sangue era suficiente para o reconhecimento da descendência negra do indivíduo, o que implicava em sua exclusão e negação de uma série de direitos e possibilidades.

5 Isso não significa que não tenha havido "cruzamento entre as chamadas raças superiores e as inferiores nos Estados Unidos”, como adverte Kabengele Munanga (1999, p. 93).

${ }^{6}$ Assim que, nos Estados Unidos, o branqueamento, pela miscigenação, por mais completo que seja, não implica incorporação do mestiço ao grupo branco. (NOGUEIRA, 2006, p. 294).

${ }^{7}$ Os senhores foram eximidos da responsabilidade pela manutenção e segurança dos libertos, sem que o Estado, a Igreja ou qualquer outra instituição assumissem encargos especiais (FERNANDES, 2008, p. 29)
} 
do registro de padres "de cor" que foram ordenados, o que era, a princípio, proibido (MATTOSO, 2003, p. 216).

Ianni fornece interpretação mais abrangente da relação entre escravidão, raça e classe na América Latina e Caribe (1978, p. 51-80). O autor compreende que o povo africano foi transformado no "negro" e no "mulato" brasileiro, produtos da escravatura enquanto processo de aculturação forçada. Essas categorias passam a ser tidas como elemento estranho nas sociedades e, mais, como subalternos - seriam a terceira raça, após o branco e o índio ${ }^{8}$. O recrudescimento do capitalismo ocasiona novas tensões e ressignificações sobre esse panorama, mas não eliminam o caráter eminentemente racial do debate: "O negro e o mulato com frequência são duplamente alienados, porque são alienados como membro de uma raça diferente, inferior, em face do branco e como membro de uma classe social também subordinada a outra, na qual a maioria pode ser branca" (IANNI, 1978, p. 76-77).

Na transição entre os séculos XIX e XX, essas são as bases históricas e sociais que criam espaço fecundo para o estabelecimento de uma suposta "democracia racial", proclamada e exaltada por Freyre (2003). O "mulato" é eleito como personagem que reduz o “descontentamento entre as raças" (MUNANGA 1999, p. 84-89), afinal, entre os brancos e negros, ele é o elo, indivíduo de cor suficientemente clara para encarnar livres e amplas possibilidades de ascensão social, de sucesso profissional e de entabulamento de relações sociais (conjugais, afetivas e sexuais). Essa projeção se agiganta no sistema capitalista, sob a égide de uma falaciosa meritocracia que reforça o delírio imposto de que tudo pode quem emprega em sua atividade o esforço necessário. As eventuais vitórias dos sistematicamente excluídos são projetadas como vitrine, ocultando-se o seu caráter excepcional, resultado de muita luta para rompimento das barreiras institucionalizadas.

A condição do negro e do "mulato" na construção da identidade nacional também é narrada por Ribeiro. $\mathrm{O}$ autor recusa as bases propostas por Freyre e chega a reconhecer como racista a proposta de desaparecimento do negro pela mestiçagem; analisa criticamente o censo de 1950 e reconhece as altas taxas de analfabetismo, criminalidade e mortalidade dos negros como expressão de um fracasso da sociedade em cumprir o ideal professado de uma

\footnotetext{
${ }^{8}$ A visão é confirmada por Schwarcz ao analisar artigos do Instituto Histórico e Geográfico Brasileiro: "Com relação à população negra vigorava uma visão evolucionista mas determinista o que se refere ao 'potencial civilizatório dessa raça': 'Os negros representam um exemplo de grupo incivilizável', afirmava $\mathrm{m}$ artigo publicado em 1891; 'As populações negras vivem o estado mais baixo da civilização humana', ponderava um ensaio de 1884. (1993, p. 111)

${ }^{9}$ Ribeiro define assim o dilema do mulato: "Posto entre dois mundos conflitantes - o do negro, que ele rechaça, e o do branco, que o rejeita -, o mulato se humaniza no drama de ser dois, que é o de ser ninguém" (2876/6640)
} 
democracia racial e detecta que a atmosfera de fluidez inter-racial funcionou como elemento dissuasivo do negro para a sua luta específica. É incompreensível como, partindo dessas premissas, o autor consegue asseverar que o preconceito racial do Brasil atua mais como força integradora do que de segregação e declarar que o racismo se circunscreve a uma questão de pele, com a possibilidade de inclusão total dos negros que se integrem a grupos de convivência de brancos (2014, p. 2905; p. 3017-3024; p. 2920-2921; p. 3038-3039; p. 28952896). A sua compreensão não só é contraditória, como marcada por uma impropriedade com a realidade que lhe era contemporânea e, mais ainda, com a dos dias atuais.

\subsection{CONSTRUINDO A DIFERENÇA: O CORPO BRANCO COMO PARADIGMA E A INTROJEÇÃO DA DISCRIMINAÇÃO}

As estruturas racistas edificadas secularmente sob esses matizes têm se disseminado com consequências irreparáveis. A construção da identidade do povo negro sofre os influxos profundos, constantes e institucionalizados das orientações discriminatórias, a ponto de reclamar e receber atenção da sociologia, antropologia e da psicologia. Esses campos do saber se debruçam sobre o tema e evocam ferramentas que auxiliam a compreensão do porquê a seletividade do sistema de justiça criminal e o genocídio do povo negro têm sido amplamente aceitos.

A condição de "diferente" na qual tem sido enquadrado o negro não abriga noção de neutralidade. Ao revés, o define em relação ao outro, o branco, tomado como paradigma e único modelo identitário aceito. Mais precisamente: homem, branco e heterossexual, são as credenciais da existência permitida, já que seu oposto estaria diretamente associado a condições primitivas, à sujeira, à ausência de valores, civilidade, humanidade (SOUSA, 1983, p. 25-32). A esse pensamento adere Fanon, quando afirma:

Para o negro só existe uma porta de saída, que dá no mundo branco. Donde a
preocupação permanente em atrair a atenção do branco, esse desejo de ser poderoso
como o branco, essa vontade disseminada de adquirir as propriedades de
revestimento, isto é, a parte do ser e do ter que entra na constituição de um ego.
$(2008$, p. 60)

A mutilação da individualidade dos homens e mulheres negras se expressa no âmbito corporal de maneira notável. O corpo branco representa o que é belo, invejável, digno de consideração e apreço, o que usualmente conduz o indivíduo a uma deformação do corpo negro para assemelhar-se àquele padrão (SOUSA, 1983, p. 57). Desde pequenas, as crianças negras são acostumadas a ouvir toda sorte de comentários, muitos em tom jocoso, que 
associam a sua estética a animais primevos, atrelados à feiura, afinal os "traços negroides" inabilitam seu portador para as uniões afetivas (NOGUEIRA, 1985, p. 82). Em aparente paradoxo - que a compreensão do ser coisificado desfaz - os atributos físicos indesejados dos negros e negras não lhe impedem de figurar como objeto de satisfação dos desejos sexuais do repertório fetichista branco, "como se fosse impossível tratar de raça sem tratar de sexo ou de sexualidade" (CORRÊA, 2007, p. 3990).

O corpo masculino é fragmentado em partes: "as marcas corporais da raça (cabelo, feições, odores); os músculos ou força física; o sexo, genitalizado dimorficamente como o pênis, símbolo falocrático do plus de sensualidade" (PINHO, 2004, p. 67). Com o corpo feminino ocorre igual reificação: a preta é a mãe que cria e o peito que amamenta os filhos brancos alheios, a trabalhadora doméstica pressionada para satisfazer os apetites sexuais dos patrões e de sua prole, o objeto da cópula ao qual se nega o direito ao prazer, a vítima de assédios dentro e fora das relações amorosas; é a tachada de "negra prostituta que tá com gringo para se dar bem", a amante oculta do homem opressor que se envergonha de assumi-la publicamente, aquela que encara usualmente a solidão, diante da ausência de parceiros que sustentem com seriedade e companheirismo uma relação fixa, como ressalta Pacheco em sua pesquisa "Branca para casar, mulata para f..., negra para trabalhar (2008, p. 91; p. 105; p. 121; p. 122; p. 291-301).

Do corpo à psique, a opressão se apresenta com peculiaridades. O legado racista diuturnamente atualizado reverbera no âmbito psicológico e representa substrato suficiente para a construção de obstáculos impostos, autoimpostos e aceitos no nível inconsciente de todas pessoas (negras e brancas). Provém da neurociência grande contribuição nesse sentido, tendo em vista que seus estudos permitem compreender como o cérebro se comporta, especialmente no que tange ao seu funcionamento por associação.

A evolução e formatação dos arranjos cerebrais tal qual conhecidos atualmente se deram num contexto marcado por duas necessidades, eventualmente coincidentes: de economia de energia e de associação ou categorização. Na savana africana ${ }^{10}$, associar o animal com quatro patas, grande juba e dentes afiados a um bicho violento que morde e mata permitiu a sobrevivência do segundo homem a ser atacado por um leão (MLODINOW, 2013,

\footnotetext{
${ }^{10}$ Nesse sentido, Mlodinow: "A evolução do cérebro acontece no decorrer de muitos milhares ou milhões de anos, mas nós vivemos numa sociedade civilizada há menos de $1 \%$ desse tempo. Isso significa que, embora possamos estar com a mente lotada de conhecimentos do século XXI, o órgão dentro do crânio ainda é um cérebro da Idade da Pedra" (2013, p. 2336-2338).
} 
2643). O resgate de uma informação pretérita para encarar o presente propicia menor gasto energético, objetivo constante do cérebro - que consome bastante no seu funcionamento. $\mathrm{O}$ aspecto problemático da associação é que, a despeito de a organização recente e contemporânea da sociedade não a exigir para a sua imediata sobrevivência, ela é em tal grau inerente que acaba sendo empregada a todo tempo na categorização do mundo à sua volta.

Assim, em razão do repertório discriminatório construído e renovado, o cérebro humano parte de aspectos fenotípicos (por exemplo, os "traços negroides") para intuir comportamentos, posturas, origem, classe social, profissão, identidade de gênero, sexualidade etc. A neurociência chama essa "intuição" de "sistema 1", expressão do cérebro que funciona automaticamente, de maneira rápida e sem filtro anterior consciente (KANEHMAN, 2012, p. 2853). É ele que fornece as necessárias respostas imediatas às situações com as quais uma pessoa se depara e é base para a compreensão do "preconceito implícito" (sexista, heteronormativo e classista) que caracteriza a sociedade brasileira é assimilado pelo indivíduo desde a mais tenra infância e repercute institivamente nas suas ações (preferências e aversões) ao longo da vida ${ }^{12}$. Como adverte Mlodinow, "ainda que sua avaliação de outra pessoa possa parecer racional e deliberada, ela é informada por processos automáticos e inconscientes- os tipos de processo reguladores da emoção sediados no córtex pré-frontal ventromedial" (2013, p. 2853-2856).

É imprescindível registrar que o caráter implícito e o automatismo do preconceito não são sinônimos de irreversibilidade, tampouco escusam o comportamento eugênico, mas auxiliam na compreensão da dificuldade de enfrentamento do racismo e no entendimento do porquê o negro também assimila a rejeição à categoria que integra. É nesse quadrante que se circunscreve a amputação ou limitação do “eu possível”, restrição às esferas de projeção do "eu negro" em posições de destaque e poder. Essa ausência de movimento é explicada pela inexistência de representatividade, ainda quando a capacidade do sujeito é manifesta e não há mensagem expressa proibitiva do acesso e da inclusão.

\footnotetext{
${ }^{11}$ A psicologia social se utiliza de uma ferramenta adotada por Harvard para medir o grau inconsciente de associação de traços a categorias. Trata-se do "Teste de Associação Implícita" (TAI), disponível na internet no site https://implicit.harvard.edu/implicit/brazil/.

${ }^{12}$ Em estudo realizado na cidade de Iowa, pessoas malvestidas foram dispersas em lojas de departamentos ao mesmo tempo que pessoas bem trajadas. Ambos os grupos foram instruídos a praticar a mesma ação: subtrair objetos das lojas, colocando-os sob as vestes. Majoritariamente, os clientes verdadeiros que viam o furto reagiam de modo bastante diverso, tolerando as condutas dos bem vestidos e, em relação aos malvestidos, além de denunciar e repudiar sua conduta, não raramente vociferavam palavras de ódio. (MLODINOW, 2013, p. 27502769)
} 


\section{DOS PARADIGMAS DA CRIMINOLOGIA AO ESTÁGIO ATUAL DO SISTEMA DE JUSTIÇA CRIMINAL NO BRASIL}

O debate qualificado sobre o sistema de justiça criminal brasileiro é feito sob a luz da Criminologia Crítica para que se possa entender a gestão do corpo negro como resquício e reinvenção do paradigma opressor baseado em questões eminentemente raciais. A discussão se torna inadiável em razão dos crescentes números do encarceramento, tortura e extermínio do povo negro, mas deve ser feita consciente do que Andrade chama de "déficit decisório". A expressão é advertência a dissociação entre as noções criminológicas e as "diversas instâncias de poder e de decisão do circuito muito fechado do controle penal, sejam legislativas, administrativas (policiais, penitenciárias), ministeriais ou judiciais". Nesse contexto, operadores do direito que adotam posturas contramajoritárias têm sido estigmatizados e punidos pela sociedade, meios de comunicação e os próprios órgãos administrativos que integram (ANDRADE, 2015. p. 7-12).

Para a análise da interação entre criminologia e a questão racial, adota-se a organização e síntese feita por Duarte, Queiroz e Costa, para quem três paradigmas teriam se sucedido na história da criminologia: o paradigma etiológico, o paradigma da reação social e o paradigma atual (2016).

O paradigma etiológico é próprio da Escola Positiva italiana da década de 1870. A época é de efervescência do conhecimento científico pautado pela causalidade como explicação para os eventos, forma de pensar transposta para o estudo do crime e do criminoso. Segundo Baratta, a criminologia desse período se apoiava numa concepção do fenômeno criminal como realidade ontológica, preexistente em relação à reação social sobre as transgressões e à criação das normas penais, o que conferiu a possibilidade de estudá-lo sob a ótica causal (2002, p. 40) ${ }^{13}$.

A Escola Positiva tem como um dos seus expoentes o professor de psiquiatria e antropologia criminal Lombroso, cujo estudo de maior destaque se expôs na famigerada obra L'uomo delinquente (1896). O autor se baseou na crença em traços ancestrais que reapareceriam acidentalmente no curso da evolução humana, originando o "criminoso nato", pessoa portadora de um atavismo ou condição primitiva. O seu método consistia em espécie

${ }^{13}$ No mesmo sentido, Zaffaroni (2014, p. 9). 
de catalogação de pessoas aprisionadas com verificação das suas "deformidades" e enunciação de suas respectivas "patologias", reveladoras da sua propensão ao crime.

A crítica de Miralles denuncia a fragilidade e precariedade da cientificidade lombrosiana. Dentre suas quatro contundentes observações, sobressai a deficiência de origem na pesquisa de Lombroso: a opção por estudar indivíduos encarcerados encerra um estereótipo, porque o recorte não alcança as pessoas criminosas que estão fora dos presídios. Esse proceder desconsidera por completo a seleção feita pelo sistema de controle penal de quem deve ou não ser detido (1983, p. 51-67). Pode-se concluir que o "homem delinquente" do médico italiano não é nada além do homem aprisionado, numa clara distorção científica.

O segundo momento apontado pelos autores é a adoção do paradigma da reação social, na década de 1960. Com ele, a criminologia se volta ao seu primeiro estágio e o aponta como expressão do racismo, por se amparar em distinções construídas e cristalizadas que permitiram a eleição de determinadas raças como inferiores. Esse novo paradigma traz consigo uma redefinição e ampliação do objeto da criminologia, abandonando a estrutura auxiliar e legitimadora do sistema oficial para criticá-lo (MOLINA, 2003, p. 1185). Ao se contrapor ao etiológico, adota categorias como "vulnerabilidade" e "seletividade", capazes de fornecer uma leitura adequada do crime e do criminoso.

A ideia do crime como uma atribuição e não um dado ontológico permanecerá no repertório da criminologia. Com isso, nega-se a existência do delito para considerá-lo "um equívoco linguístico" e afirmar que "só existem conflitos arbitrariamente selecionados, e, juridicamente, somente um conjunto muito heterogêneo de hipóteses conflituosas, com muito boa vontade, podem ser chamados de "delitos" (ZAFFARONI, 2015, p. 247-248) ${ }^{14}$. É com base nessa percepção que se alerta para os reflexos da construção racista da sociedade brasileira nos números do cárcere, da tortura e da violência (a seguir apresentados), como um retrato confirmado do processo de gestão do corpo negro em suas diversas etapas.

A seletividade do sistema penal se lastreia na construção da figura do "inimigo", admitida pelo direito penal do século $\mathrm{XX}$ ao considerar algumas pessoas como perigosas e indesejadas. Naturalmente, esses indivíduos serão recrutados dos grupos vulneráveis da

\footnotetext{
${ }^{14} \mathrm{O}$ pensamento converge com o de Andrade: "Uma conduta não é criminal 'em si' (qualidade negativa ou nocividade inerente) nem seu autor um criminoso por concretos traços de sua personalidade ou influências de seu meio-ambiente. A criminalidade se revela, principalmente, como um status atribuído a determinados indivíduos mediante um duplo processo: a 'definição' legal de crime, que atribui à conduta o caráter criminal e a 'seleção' que etiqueta e estigmatiza um autor como criminoso entre todos aqueles que praticam tais condutas" (1995, p. 28).
} 
sociedade, aplicando-se-lhes uma etiqueta (teoria do labeling approach $^{15}$ ) em razão do incômodo real, imaginário ou potencial que provocam (ZAFFARONI, 2014, p. 70-82). Essa visão permitiu a coisificação de alguns grupos e a sua consequente segregação ou eliminação, processos maquiados pela racionalização que os têm acompanhado, num nítido esforço justificativo que visa legitimar as iniquidades (ZAFFARONI, 2014, p. 18).

Essa compreensão genérica do processo de seleção de condutas e pessoas é descrita por grande parte dos autores em criminologia, mas é Flauzina quem o interpreta sob o inadiável aspecto racial. A autora problematiza a construção da relação entre racismo e sistema penal sob a ótica de um discurso oficial da inexistência de discriminação para concluir:

\begin{abstract}
Dessa forma, elegendo o sistema penal como a via a nos conduzir à elucidação da plataforma de caráter genocida do Estado, é fundamental observarmos o nível de seu comprometimento como a variável racial. Atentando para a movimentação do referido sistema ao longo da história, podemos perceber um padrão que se sofistica, sem se modificar substancialmente. Tudo indica que as bases de atuação do sistema penal brasileiro nunca conseguiram se divorciar de seu passado colonial por completo, arrastando para a contemporaneidade vestígios de um direito penal de ordem privada. $\mathrm{O}$ projeto que preside sua atuação, portanto, é em grande medida, herdeiro do estatuto escravocrata. (2006, p. 41-42)
\end{abstract}

É sobre esse viés que se pode compreender o estágio atual da criminologia, apondo as lentes no seu devido lugar para o enfrentamento dos problemas.

Ainda na visão de Duarte, Queiroz e Costa (2016), o terceiro paradigma em criminologia seria marcado por uma contradição: a coexistência entre movimentos que pugnam pelo desencarceramento, através das mais variadas propostas (abolicionismo, minimalismo, garantismo etc.), e a mantença do caráter seletivo do sistema de justiça criminal, ainda que se utilizando, eventualmente, de medidas coercivas não encarceradoras. Esse estágio carrega, no que parece sua incoerência, a decodificação do problema. Ao se alcançar a fase mais consciente dos equívocos da política de repressão à criminalidade, deixase claro que a continuidade da adoção de um sistema lastreado nos atuais pressupostos simboliza um ato político deliberado - e não possível ou suposta ignorância. Se as taxas de encarceramento e os números elevados do homicídio no Brasil expõem as entranhas de um

\footnotetext{
15 “As teorias do etiquetamento ou da reação social (labeling approach) refutaram, diante de tudo, a vigência do princípio da 'igualdade', ao explicitar que o desvio e a criminalidade não são entidades ontológicas préconstituídas - qualidades negativas da ação criminal em si, inerentes a ela -, mas etiquetas eu determinados processos de definição e seleção, altamente discriminatórios, por certo, colocam a certos sujeitos, de forma muito desigual e através de complexos mecanismos de interação, que seguem os mesmos critérios e distribuição dos demais bens sociais positivos: o 'papel', o 'status'; e sem que o concreto comportamento do estigmatizado explique o desencadeamento daqueles processos, em mereça a etiqueta recebida" (MOLINA, 2003, p. 11921193, tradução nossa).
} 
país que escolhe quem prende, quem mantém preso sob tortura e quem é morto, é possível diagnosticar com mais facilidade os caminhos que o debate precisa trilhar.

\subsection{OS NÚMEROS DA GESTÃO DE CORPOS NEGROS NO BRASIL}

A crescente violência no Brasil é constante propulsora de debates sobre as possíveis formas de enfrentamento. Cotidianamente, voltam à pauta propostas de endurecimento da legislação penal, sob o antiquado, recorrente e falacioso argumento de que o "Brasil é o país da impunidade". O inchaço das normas penais incriminadoras não tem sido obstáculo a novas criações, como se observa, por exemplo, da insistente ampliação da Lei de Crimes Hediondos (Lei n. 8.072/1990 ${ }^{16}$ ). Persiste a adoção de um modelo de política-criminal apoiado em ações simbólico-legislativas como resposta a problema reais. Apoiado numa "cultura do medo" (PASTANA, 2003), esse discurso do endurecimento aglutina diversos setores da sociedade civil, é majoritariamente encampado pelas instituições jurídicas, defendido por parte da academia e, não raro, reúne representantes com orientação político-partidária extremamente opostas - o que dá noção da magnitude da sanha punitivista. Como adverte Freitas, esse cenário "cria situações desafiadoras em termos de um efetivo controle social e político dos delitos e transgressões praticados na sociedade" (2015, p. 13).

Todo esse arcabouço populista se manifesta em duas etapas da gestão do corpo negro no Brasil: o manejo do sistema de justiça voltado ao aprisionamento seletivo - com a permissividade da tortura no cárcere; a de extermínio do povo negro, ora consentido, ora praticado diretamente pelas agências do estado.

O hiperencarceramento brasileiro é uma realidade conhecida e amplamente noticiada. Consta dos debates acadêmicos e políticos, em geral dissociados de qualquer esforço real para a sua reversão, muito porque costuma ser veiculada por interlocutores completamente alheios aos grupos usualmente tragados pelo sistema penal. A "infantilização" do negro, pontuada por Nascimento (1978, p. 27) e Gonzales (1984, p. 225), relembra da histórica e recorrente usurpação do lugar de fala de quem sente no dia a dia as dores do alijamento (algo ainda mais grave no que toca as mulheres), o que permite sepultar a

\footnotetext{
${ }^{16}$ A lei dos crimes hediondos têm sido alterada com intensa frequência, sempre que se deseja "combater" determina conduta detectada na sociedade ou "proteger" certos grupos atingidos pela violência. Nos últimos 10 anos, o diploma foi alterado pela lei ${ }^{\circ} 13.142$, de 2015 , que incluiu o homicídio e a lesão a agentes da segurança pública como crime hediondo; pela lei $\mathrm{n}^{\circ} 13.104$, de 2015 , que adicionou o feminicídio ao mesmo rol; pela lei $\mathrm{n}^{\circ}$ 12.015/2009, que alterou a concepção de estupro, atentado ao pudor e criou o estupro de vulnerável e pela lei no 11.464/2007, que dispôs sobre fiança, regime de cumprimento de cumprimento e outros aspectos processuais ou de execução da pena.
} 
persistente oposição às ações afirmativas na graduação, pós-graduação e concursos públicos do país. "Denegrir" os espaços de produção científica ${ }^{17-18}$ e, amplamente, de poder, é uma das vias mais eficazes para aproximar o discurso inconformado com a seletividade do sistema punitivo da realização prática de mudanças.

Segundo o Levantamento Nacional de Informações Penitenciárias, o Brasil ostenta a $4^{\mathrm{a}}$ maior população carcerária do mundo, em termos absolutos. São contabilizados assustadores 622.202 corpos privados de liberdade, número que nos coloca atrás apenas de Estados Unidos, China e Rússia, respectivamente. Para se ter uma noção, a Índia, quinto colocado, possui 200 mil presos a menos, embora tenha uma população 6 (seis) vezes maior que a brasileira (2014b). Todos os três países de lista apresentam taxa de redução do aprisionamento desde 2008 (destaque para a Rússia, com 24\% de retração), enquanto o Brasil insiste no controle através da prisão, com $33 \%$ de crescimento no período, proporção suficiente para que se ultrapasse a Rússia em 2018 (2014a, p. 14-15).

Uma característica peculiar é o significativo percentual de 40,1\% de presos provisórios, o que representa quase 250 mil pessoas privadas de liberdade sem resposta definitiva do Judiciário acerca da sua culpabilidade (2014b). Esse dado corporifica o prenúncio de Zaffaroni sobre o perfil do encarceramento na América Latina, essencialmente vinculado ao "sistema penal cautelar" (2015, p. 111). Isso significa que o retrato do cárcere está associado menos às reformas estritamente penais e mais ao tratamento que o processo penal dá às ferramentas cautelares de aprisionamento, como as prisões em flagrante ${ }^{19}$, temporária e preventiva. Efetivamente, ao prender tantas pessoas antes da decisão final do

\footnotetext{
${ }^{17}$ Sobre o tema, afirma Carvalho: "O nosso racismo acadêmico específico, vivo até hoje, não foi apenas consequência, então, de um racismo gerado na estabilização da escola básica, mas uma produção combinada de um mecanismo geral de exclusão racial planejado e executado com eficácia (...)” (2005-2006, p. 100).

${ }^{18}$ Abordando a representatividade na academia, Santos pondera: "A sociedade brasileira dá fortes indícios de que pensar em mudanças sociais radicais significa pensar em atividades imediatas, como greves, piquetes nas ruas, paralisações e outras formas que tenham como limite o tempo e a viabilidade; entretanto, o trabalho intelectual também pode ser uma forma de luta que visa a contribuir para a transformação social, mas nem sempre é valorizado ou concebido como forma eficaz de luta" (2006, p. 161).

${ }_{19}$ Apenas em 2011, com a Lei $\mathrm{n}^{\circ} 12.403$, a legislação processual passou a exigir que o magistrado se posicionasse expressamente acerca da prisão em flagrante realizada pela autoridade policial. Até então, não raro pessoas passavam todo o trâmite judicial presas sem que houvesse decisão judicial justificando as razões da prisão, apenas por terem sido flagradas em situação de suposto cometimento de delito. De todo modo, essa realidade só virá a ser efetivamente alterada no plano fático com a implementação em larga escala das Audiências de Apresentação (ou de Custódia, como se inste em chamar), já normatizadas através da Resolução $\mathrm{n}^{\circ} 213$, de 15 de dezembro 2015.
} 
processo, o Estado não se esforça para ocultar uma opção irresponsável e claramente incompatível com o princípio da presunção de inocência ${ }^{20}$.

A investigação sobre a seletividade do sistema de justiça criminal ressalta informações que se conectam diretamente com o legado escravocrata: a cada três pessoas presas no Brasil, duas são negras; enquanto a população brasileira é de $51 \%$ de negros, o percentual de negros encarcerados é de 61,67\%. Está escancarada a sobrerrepresentação do povo negro no sistema penitenciário, que se distribui desta maneira entre as regiões: no Norte, 76/83\%; Nordeste, 71/80\%; Centro-Oeste, 57/73\%; Sudeste, 42/72\% e Sul do país, 21/33\% Esse panorama desbanca eventual argumento de que a composição majoritária de negros no Brasil teria como natural consequência o seu aprisionamento predominante (DEPEN, 2014, p. 51).

A gestão do encarceramento definitivamente não é marcada pela aleatoriedade. Os aprisionados no Brasil são predominantemente jovens, sendo de 55,07\% a taxa das pessoas entre 18 e 29 anos no cárcere, enquanto essa faixa etária corresponde a apenas 18,90\% do povo brasileiro. Ainda que o Levantamento não faça o cruzamento entre raça e idade, é de se supor que esses jovens são também majoritariamente negros. Outro aspecto é seu grau de instrução, já que $75,08 \%$ da população prisional é composta por analfabetos, alfabetizados informalmente e pessoas com ensino fundamental completo (2014b).

$\mathrm{O}$ aprisionamento feminino convoca à reflexão por outras razões. Embora os números absolutos apontem para uma representação de apenas 6,4\% do total de pessoas encarceradas, o aumento do contingente feminino nos presídios brasileiros foi de $567 \%$ entre os anos 2000 e 2014, somando 37.380 mulheres ao final do período. Essas mulheres são majoritariamente negras (67\%), jovens (50\% têm entre 18 e 29 anos), de baixa escolaridade (somente $11 \%$ completaram o ensino médio) e costumam sofrer total desamparo em caso de gravidez ou maternidade nos estabelecimentos prisionais ${ }^{22}$. Num país com as tradições já anunciadas, não se pode atribuir esses números a coincidências. Se há alguma relação de causalidade, deve ser atribuída à "política de repressão às drogas" (leia-se às pessoas que comercializam drogas) que, a par de ser responsável pelo encarceramento de $27 \%$ do sistema

\footnotetext{
${ }^{20}$ A decisão do Supremo Tribunal Federal ao julgar o Habeas Corpus no 126.292 e as Ações Declaratórias de Constitucionalidade n. 43 e n. 44, autorizando a prisão decorrente de acórdão proferido por tribunal caminha na mesma linha da crítica do autor e afronta igualmente o princípio da presunção de inocência.

${ }^{21}$ Manteve-se o mesmo paralelo: o primeiro percentual indica o número de pessoas negras na população, enquanto o segundo, pessoas negras encarceradas na região.

${ }^{22}$ Apenas $49 \%$ das unidades femininas possui dormitório adequado para gestante e $76 \%$ não dispõem de creche (sendo que, no primeiro caso, dos $51 \%$ restante, $17 \%$ não prestaram informação).
} 
global, incide de maneira muito mais específica entre as mulheres, atingindo a absurda marca de $68 \%$ das encarceradas (DEPEN, 2014).

Do Brasil do século XIX ao Brasil atual, o destino do homem e da mulher negra segue gravado pela indignidade politicamente conduzida pelos grupos dominantes. O perfil das pessoas encarceradas mostra que a prisão não é o início de um processo de exclusão, mas seu fim, com a contenção das pessoas já alijadas socialmente - recordando-se que o componente social, no Brasil, tem cor. O quadro é mais drástico do que o suposto porque as condições do cárcere são completamente inadmissíveis. Há um déficit de 250.318 vagas no sistema prisional $^{23}$, o que significa que em celas mal areadas e insalubres estão amontoadas 16 (dezesseis) pessoas onde caberiam 10 (dez) (DEPEN, 2014b).

O rol de absurdos consentidos no cárcere brasileiro é interminável, a ponto de ter sido declarado o "Estado de Coisas Inconstitucional" do sistema carcerário, em ação julgada pelo Supremo Tribunal Federal (ADPF n. 347). Além da insuficiência de vagas, por si só degradante da condição humana, os presídios informam altas taxas de tortura, adoecimento ${ }^{24} \mathrm{e}$ mortalidade violenta.

A Pastoral Carcerária realizou, em 2016, Relatório sobre a tortura cuidando de 105 casos de pessoas presas e familiares de pessoas presas em 16 estados brasileiros e no Distrito Federal. O trabalho desnuda uma constante de violências assim distribuídas: agressões físicas (70\%) e verbais (35\%), violência sexual (6\%), tratamento humilhante ou degradante (37\%) e condições degradantes de aprisionamento $(71 \%)^{25}$. As mulheres são especialmente vulneráveis, de acordo com o estudo: embora sejam menos de $7 \%$ da população carcerária, concentram entre 27 e $43 \%$ das denúncias de tortura, sobretudo aquelas relacionadas à violência sexual (2016).

Além da morte-em-vida que toda essa teia de números representa, a morte intencional (excluídos os óbitos por razões de saúde) nos presídios do país é algo alarmante.

\footnotetext{
${ }^{23}$ Além da tendência histórica ao crescimento, essa realidade pode se agravar drasticamente se forem cumpridos os 595.952 mandados de prisão que estão em aberto no país, segundo o Conselho Nacional de Justiça (2015).

${ }^{24}$ As doenças e os agravos (O Ministério da Saúde define a notificação compulsória de doenças e agravos através da Portaria $\left.\mathrm{n}^{\circ} 1.271 / 2014\right)$ são também habituais nas prisões. Embora não haja dados para identificar a exata origem das doenças (se precedentes ou posteriores), fato é que, para cada cem mil presos, 1215,5 são soropositivos, proporção sessenta vezes maior que a taxa da população total e 940,9 pessoas apresentam tuberculose, frequência 38 vezes maior que nas taxas globais. A assistência à saúde demanda estrutura inexistente nos estabelecimentos prisionais do país.

${ }^{25}$ São registradas múltiplas formas de agressão, o que resulta em somatório superior a $100 \%$.
} 
No primeiro semestre de 2014, excluídos os dados de São Paulo e Rio de Janeiro ${ }^{26}$, morreram 8,4 pessoas para cada 10 mil pessoas presas, com destaque para o estado do Maranhão (onde fica o presídio de Pedrinhas), que apresentou taxa de 72 óbitos por 10 mil habitantes. Isso corresponde a 167,5 mortes intencionais para cada cem mil pessoas presas em um ano (DEPEN, 2014a, p. 115). Nos presídios brasileiros, as pessoas morrem 3 vezes mais que na população em geral, consideradas as mortes intencionais (DEPEN, 2014b, p. 51).

\subsection{GENOCÍDIO DO POVO NEGRO: A INTERDIÇÃO QUE EXPLICA O CONSENTIMENTO}

O último e mais relevante ponto a tocar quando se trata da gestão do corpo negro no Brasil é o genocídio ${ }^{27}$, praticado ou consentido pelas autoridades, com chancela e aceitação social. Aproximar-se do tema é perceber que contenção, exclusão e tortura são práticas que coexistem com a matança espacializada e direcionada. No Brasil, existem vidas construídas para não importar, vidas negras que podem ser alvo de toda sorte de violência e aniquilamento sem que haja desconforto geral.

Entre janeiro de 2011 e dezembro de 2015, foram contabilizados 279.567 mortos no país, cifra que supera as da Guerra na Síria. Só no ano de 2015 foram 58.467 pessoas mortas por ações violentas intencionais. Além de uma história de vida, geralmente associada a exclusão, esses cadáveres têm cor e idade: $73 \%$ das vítimas, um total de 42.680 pessoas, são pretas e pardas; 54\%, ou 31.572, são jovens. Por que os números, tão hiperbólicos, produzem pouco ou nenhum assombro?

A ausência de iniciativas públicas alinhadas a partir de um fio condutor transversal que visualize a questão racial para a contenção efetiva da violência que mata negros e jovens (CARNEIRO, 2011) torna inegável a existência de uma política da morte em curso no país. A "necropolítica” (MBEMBE, 2011) ${ }^{28}$ se dá não só por essa perceptível omissão, mas também

\footnotetext{
${ }^{26}$ Os estados não forneceram os dados necessários, segundo o Depen, valendo recordar que o estado de São Paulo é responsável pelo maior número de presos do país.

${ }^{27} \mathrm{O}$ uso da expressão "genocídio" parte da ressignificação do termo feita por Flauzina, ao demarcar a construção eurocêntrica do conteúdo dado à expressão, sua dimensão simbólica ligada ao Holocausto e a necessidade de alargar a sua compreensão para alcançar outras violações de grupos sociais semelhantes, inclusive desafiando os sistemas de supremacia branca (2014). A terminologia é aplicada na análise do cenário da morte na cidade de Salvador por Cappi e Ferreira: "Portanto, um elemento importante que norteia o genocídio da população negra é o racismo em sua forma sofisticada, na qual a negação de sua existência e a ideia de harmonia entre as raças acaba alimentando a manutenção das estruturas de poder. Isto permite que a declaração se torne, neste caso, desnecessária" (2016, p. 562).

${ }^{28}$ Mbembe assevera: "Na economia do biopoder, a função do racismo consiste em regular a distribuição da morte e em fazer possíveis as funções mortíferas do Estado" (2011, p. 23, tradução nossa).
} 
através de ações palpáveis. Segundo o Fórum Brasileiro de Segurança Pública, o aparato repressivo policial vitimou, apenas em 2015, 3.320 pessoas. A polícia brasileira ostenta a inaceitável taxa de letalidade ${ }^{29}$ de 1,6 brasileiros mortos para cada 100 mil habitantes, mais do que Honduras, país mais violento do mundo (2016). Detrás do que poderia ser mero "desvio de conduta policial" se encobre verdadeira política de Estado, à medida que outras agências do sistema penal têm participação direta na homologação dessas mortes (ZACCONE, 2015) conferindo-lhes roupagem jurídica e judicial que busca beatificar a intervenção policial - e simboliza a segunda morte dessas mesmas vítimas.

Essa é somente uma das peças do quebra-cabeça do padrão genocida. As políticas de opressão e silenciamento têm sido espacializadas, ou seja, "alguns corpos e alguns territórios racializados recebem a preferência na distribuição das chances de vida e morte" (ALVES, 2011, p.117-118). Isso se percebe em duas frentes: a ocupação das agências de repressão estatal em bairros e comunidades tradicionalmente ocupados por maioria negra e o elevado índice de mortes nessas localidades.

A título de exemplo, recorde-se que, no ano de 2011, o estado da Bahia deu início ao chamado "Pacto pela Vida" ${ }^{30}$, programa similar ao "Programa fica vivo", de Minas Gerais; "Unidades de Polícia Pacificadora", do Rio de Janeiro; "Estado Presente”, do Espírito Santo; “Alagoas pela Paz", de Alagoas, dentre outros ${ }^{31}$. A tônica que parece ser comum entre eles é a adoção de medida simbólica, que oculta a mesma lógica de governança espacial da morte. No caso baiano, a principal "vitrine" do Pacto é a instalação das chamadas "Bases Comunitárias", o que ocorreu na capital, Salvador, e em municípios do interior. Até o momento, e não por coincidência, as bases estão instaladas em localidades que concentram a população negra, ignorando "outras regiões da cidade onde as taxas de violência poderiam justificar ações

\footnotetext{
${ }^{29}$ A taxa de letalidade representa as mortes decorrentes de intervenção policial.

${ }^{30}$ Discutindo a ausência do debate sobre as questões raciais no programa estadual, Freitas conclui que: "As sucessivas chacinas com participação policial ocorridas no estado e as declarações de atores políticos locais em apoio às operações policiais que resultaram nestas chacinas, associadas à baixa efetividade de instâncias de controle da atividade policial, confirmam a anunciada persistência do genocídio negro no programa baiano. Mais do que um lapso ou uma omissão pontual este aspecto é um traço central do programa e importa no seu comprometimento político na abordagem do tema" (2015, p. 105-106).

31 Apesar da adoção de novas terminologias, pode-se dizer que a segurança pública no Brasil não avançou significativamente. Um dos traços que revela seu atraso é a inclinação pelo gerenciamento de crises em detrimento do recurso ao planejamento de médio e longo prazo. Reflexo disso é o "modismo", na década de 2010, da nomeação de delegados federais para chefia as secretarias de segurança pública - à época, eram 18 estados com essa característica (SAPORI, 2011, p.12).
} 
similares, desde que não fossem núcleos populacionais de maioria branca" (AVELAR, 2016, p. 60)

Estudo realizado por Calazans tendo como recorte a cidade de Salvador entre os anos de 2010 e 2015 demonstra que a média anual até 2014 era de 1.500 homicídios, com taxa oscilante, mas sempre acima de 70\% de jovens entre 15-29 anos. Os homicídios estão concentrados em bairros específicos, onde a população é eminentemente negra (2016, p. 572 573), vitimando-se os "homens-jovens-negros", "dimensões inseparáveis quando se trata do estudo da violência e, fundamentalmente, das mortes violentes no Brasil” (REIS, 2005, p. 94). Cerqueira e Santos chegam à conclusão análoga a de Calazans ao analisar o estado do Rio de Janeiro: "Considerando todos os controles socioeconômicos, encontramos que o indivíduo negro possui 23,5\% a mais de chances de sofrer homicídio no Rio de Janeiro, do que um indivíduo não negro, o que nos parece uma evidência do racismo que mata" (2017, p. 31$)^{32}$.

Os dados oficiais revelam que o estado domina o espaço-cidade, atua repressivamente e define quem vive e quem morre. Essa política trágica resulta em inadmissível genocídio, que somente é viável porque intencionalmente articulado com um processo de desumanização do povo negro, jovem e pobre no Brasil. A "racialização" do século XIX fez e faz do negro um "não-ser", inapto para a sociedade disciplinar. A incorrigibilidade é inerente à sua condição no mundo, o que o desqualificada para a vida e o torna descartável. (CARNEIRO, 2006, p. 126-127). É esse o substrato autorizativo do empilhamento diuturno de cadáveres negros por uma sociedade que escora na sua pretensa democracia racial as práticas permanentes de extermínio.

\section{CONCLUSÃO}

A análise dos relatórios do encarceramento, da tortura nos estabelecimentos prisionais e das mortes em geral e decorrentes de intervenção policial revelam nítida gestão do corpo negro no Brasil, operacionalizada por meio de políticas institucionais que definem quem vive e quem morre. O resgaste histórico da conformação da identidade negra permite concluir que os números superlativos são fruto da escravidão legalmente rompida, mas

\footnotetext{
${ }^{32}$ Zaffaroni também entende existir um genocídio, agravado por questões étnicas em alguns países: "Em alguns países, esta situação torna-se mais evidente quando o genocídio assume um aspecto inquestionavelmente ético, como a contribuição do sistema penal para a extinção do índio ou o nítido predomínio de negros, mulatos e mestiços entre presos e mortos" (2015, p. 125).
} 
socialmente reinventada, atualizada, sofisticada. O processo de segregação foi forjado a partir de uma suposta democracia racial que encontrou solo fecundo em um país miscigenado, onde a pretensa mobilidade do "mulato" foi utilizada como alegoria que silenciou a luta negra.

A opressão racial foi amparada pela criminologia, que inicialmente erigiu raças inferiores cuja delinquência seria atributo inato, viabilizando a construção de inimigos, pessoas selecionadas pelo sistema. Apesar da descoberta das preferências do sistema de justiça, os dados atuais não demonstram qualquer avanço na contenção da seletividade, mas um recrudescimento das políticas de segregação e extermínio dos negros no Brasil, sobretudo através da espacialização da morte - criação de espaços urbanos em que o extermínio não produz qualquer constrangimento, senão às suas vítimas diretas e indiretas.

O constante massacre em curso no país está diretamente conectado com um processo de renovada "desumanização" dos negros e negras, fundado na usurpação do seu lugar de fala e limitação das suas possibilidades identitárias. Constituído como um "não-ser", o negro é ente desimportante, cujas demandas são diuturnamente silenciadas para que a sociedade possa conviver sem perturbação com os números inadmissíveis do genocídio em curso.

\section{REFERÊNCIAS}

ALVES, Jaime Amparo. Topografias da violência: necropoder e governamentalidade espacial em São Paulo. Revista do Departamento de Geografia, São Paulo, USP, Volume 22, p. 108-134, 2011.

ANDRADE, Vera Regina Pereira. Do paradigma etiológico ao paradigma da reação social: mudança e permanência de paradigmas criminológicos na ciência e no senso comum. Revista Sequência, Florianópolis, v. 16, n. 30, p. 24-36, 1995.

Em favor da criminologia e da brasilidade criminológica em tempos de barbárie punitiva. In: CORTINA, Monica Ovinski de Camargo; CIMOLIN, Valter (Org).

Criminologia Crítica. Curitiba: Multideia, 2015. p. 5-12.

AVELAR, Laís. "O 'Pacto pela Vida', aqui, é o pacto pela morte!'”: o controle racializado das bases comunitárias de segurança pelas narrativas dos jovens do grande nordeste de amaralina. 2016. 152f. Dissertação (Mestrado em Direitos Humanos e Cidadania) - Centro de Estudos Avançados Multidisciplinares, Universidade de Brasília, DF, 2016.

BAHIA. Pacto pela vida: o que é? Disponível em: < http://www.pactopelavida.ba.gov.br/pacto-pela-vida/o-que-e/>. Acesso em: 04 abr. 2017. 
Pacto pela vida: base comunitária de segurança. Disponível em: <

http://www.pactopelavida.ba.gov.br/base-comunitaria-de-seguranca/>. Acesso em: 04 abr. 2017.

BRASIL. Conselho Nacional de Justiça. Banco Nacional de Mandados de Prisão.

Disponível em: <https://www.cnj.jus.br/bnmp/\#/relatorio>. Acesso em: 12 mai. 2017.

Fórum Brasileiro de Segurança Pública. Anuário Brasileiro de Segurança Pública 2016. São Paulo, 2016.

Instituto Brasileiro de Geografia e Estatística. Recenseamento do Brazil em 1872. Rio de Janeiro: Typ. G. Leuzinger, [1874?]. Disponível em: $<$ http://biblioteca.ibge.gov.br/biblioteca-catalogo?view=detalhes\&id=225477>. Acesso em: 24 abr. 2017.

Departamento Penitenciário Nacional. Levantamento Nacional de Informações Penitenciárias: Infopen Mulheres. Brasília: Ministério da Justiça, 2014.

Departamento Penitenciário Nacional. Levantamento Nacional de Informações

Penitenciárias: Infopen - Junho de 2014. Brasília: Ministério da Justiça, 2014.

Departamento Penitenciário Nacional. Levantamento Nacional de Informações

Penitenciárias: Infopen - Dezembro de 2014. Brasília: Ministério da Justiça, 2014.

. Supremo Tribunal Federal (STF). Ação de Descumprimento de Preceito

Fundamental n. 347. Relator: Ministro Marco Aurélio. Órgão julgador: Tribunal Pleno.

Brasília, DF, 9 de setembro de 2015. Disponível em: <

http://www.stf.jus.br/portal/peticaoInicial/verPeticaoInicial.asp?base=ADPF\&s1=347\&proces so=347> . Acesso em: 10 mai. 2017.

BARATTA, Alessandro. Criminologia crítica e crítica do direito penal: introdução à sociologia do direito penal. Rio de Janeiro: Revan, 2002. 3. ed.

CALAZANS, Márcia Esteves et al. Cadernos do CEAS, Salvador, n. 238, p. 568-594, 2016.

CARNEIRO, Aparecida Sueli. A construção do outro como não ser como fundamento do ser. 2005. 339f. Tese (Doutorado em Educação) - Faculdade de Educação, Universidade de São Paulo, São Paulo, 2005.

Racismo, Sexismo e Desigualdade no Brasil. São Paulo: Selo Negro, 2011.

CARVALHO, José Jorge. O confinamento racial do mundo acadêmico brasileiro. Revista USP, São Paulo, n. 68, p. 88-103, dezembro/fevereiro 2005-2006.

CERQUEIRA, Daniel; COELHO, Danilo Santa Cruz. Democracia Racial Homicídio de Jovens Negros na Cidade Partida. Brasília, DF: IPEA, 2017. 
CORRÊA, Mariza. Sobre a invenção da mulata. In: MELO, Hildete Pereira et al. (Org.). Olhares feministas. Brasília: Ministério da Educação, UNESCO, 2007. Edição digital. p. $3857-4123$.

DUARTE, Evandro Piza; QUEIROZ, Marcos Vinícius Lustosa; COSTA, Pedro Argolo. A hipótese colonial, um diálogo com Michel Foucault: a modernidade e o Atlântico Negro no centro do debate sobre racismo e sistema penal. Universitas Jus, v. 27, n. 2, 2016, p. 500526.

FANON, Frantz. Pele negra máscaras brancas. Salvador: EDUFBA, 2008.

FERNANDES, Florestan. A integração do negro na sociedade de classes. São Paulo: Globo, 2008. Vol. I. 3. ed.

FLAUZINA, Ana Luiza Pinheiro. O corpo negro caído no chão: o sistema penal e o projeto genocida do estado brasileiro. 2006. 146f. Dissertação (Mestrado em Direito) - Faculdade de Direito, Universidade de Brasília, Brasília, DF, 2006.

As fronteiras raciais do genocídio. Revista de Direito da Universidade de Brasília, Brasília, v. 01, n. 01, p. 119-146, jan./jun. 2014.

FREITAS, Felipe da Silva. Discursos e práticas das políticas de controle de homicídios: uma análise do "Pacto pela Vida" do Estado da Bahia (2011-2014). 2015. 159f. Dissertação (Mestrado em Direito) - Faculdade de Direito, Universidade de Brasília, Brasília, DF, 2015.

Violência real e as ciladas do punitivismo: reflexões sobre atividade policial e a lei 13.142, de 6 de julho de 2015. In: FLAUZINA, Ana Luiza Pinheiro et al. Discursos Negros: legislação penal, política criminal e racismo. Brasília: Brado Negro, 2015. p. 13-43.

FREYRE, Gilberto. Casa-grande e senzala: formação da família brasileira sob o regime da economia patriarcal. São Paulo: Global, 2003. 48. ed.

GEULEN, Christian. Breve historia del racismo. Madrid: Alianza, 2010.

GONZALES, Lélia. Racismo e sexismo na cultura brasileira. Revista Ciências Sociais Hoje, Anpocs, 1984, p. 223-244.

IANNI, Octavio. Escravidão e racismo. São Paulo: Hucitec, 1978.

KAHNEMAN, Daniel. Rápido e devagar: duas formas de pensar. Rio de Janeiro: Objetiva, 2012. Edição digital.

LOMBROSO, Cesare. L’uomo delinquente. Torino: Fratelli Bocca, 1896.

MATTOSO, Kátia M. de Queirós. Ser escravo no Brasil. São Paulo: Brasiliense, 2003.

MBEMBE, Achille. Necropolítica seguido de Sobre el gobierno privado indirecto. [S.1.]: Melusina, 2011. 
MLODINOW, Leonard. Subliminar: Como o inconsciente influencia nossas vidas. Rio de Janeiro: Zahar, 2013. Edição digital.

MIRALLES, Teresa. Patología criminal: aspectos biológicos. In: BERGALLI, Roberto; BUSTOS RAMÍREZ, Juan; MIRALLES, Teresa. El pensamiento criminológico: um análisis crítico. Bogotá: Temis Libreria, 1983. p. 51-67. Vol. I.

MOLINA, Antonio García-Pablos. Tratado de Criminologia. Valencia: Tirant lo blanch, 2003. 3. ed.

MUNANGA, Kabengele. Rediscutindo a mestiçagem no Brasil: Identidade nacional versus identidade negra. Petrópolis: Vozes, 1999.

NASCIMENTO, Abdias do. Genocídio do negro brasileiro: processo de um racismo mascarado. Rio de Janeiro: Paz e Terra, 1978.

NOGUEIRA, Oracy. Preconceito racial de marca e preconceito racial de origem: sugestão de um quadro de referência para a interpretação do material sobre relações raciais no Brasil.

Revista Tempo social. São Paulo, v. 19, n. 1, p. 287-308, nov. 2006. 1985.

Tanto preto quanto branco: estudo das relações sociais. São Paulo: T.A Queiroz,

PACHECO, Ana Cláudia Lemos. "Branca para casar, mulata para f...., negra para trabalhar": escolhas afetivas e significados de solidão entre mulheres negras em Salvador, Bahia. 2008. 317 f. Tese (Doutorado em Ciências Sociais ) - Instituto de Filosofia e Ciências Humanas, Universidade Estadual de Campinas, Campinas, 2008.

PASTANA, Débora Regina. Cultura do medo: reflexões sobre a violência criminal, controle social e cidadania no Brasil. São Paulo: IBCCRIM, 2003.

PASTORAL CARCERÁRIA. Tortura em tempos de encarceramento em massa. São Paulo: ASAAC, 2016.

PINHO, Osmundo. Qual a identidade do homem negro? Revista Democracia viva, Rio de Janeiro, n. 22, p. 64-69, jun./jul. 2004.

PROJECT IMPLICIT SERVICES. Teste de associação implícita. Disponível em: < https://implicit.harvard.edu/implicit/brazil/>. Acesso em: 18 mai. 2017.

RAMOS, Arthur. O negro Brasileiro. Rio de Janeiro: Companhia Editora Nacional, 1940. $1^{\circ}$ vol. 2. ed. argumentada.

REIS, Vilma M. dos S. Atucaiados pelo Estado: as políticas de segurança pública implementada nos bairros populares de Salvador e suas representações, 1991-2001. 247f. Dissertação (Mestrado em Ciências Sociais) - Faculdade de Filosofia e Ciências Humanas, Universidade Federal da Bahia, Salvador, 2005. 
RIBEIRO, Darcy. O povo brasileiro: a formação e o sentido do Brasil. São Paulo: Global, 2014. $1^{\text {a }}$ edição digital.

SAPORI, Luis Flávio. A segurança pública no Brasil. Em debate, Belo Horizonte, v. 3, n. 1, p. 11-15, jan. 2011.

SCHWARCZ, Lilia Moritz. O Espetáculo das raças: cientistas, instituições e a questão racial no Brasil 1870-1930. São Paulo: Companhia das Letras, 1993.

SKIDMORE, Thomas. Preto no Branco: raça e nacionalidade no pensamento brasileiro. Rio de Janeiro: Paz e Terra, 1976.

SOUSA, Neusa Santos. Torna-se negro: as vicissitudes da identidade do negro brasileiro em ascensão social. Rio de Janeiro: Graal, 1983.

SANTOS, Tereza Josefa Cruz. Professores universitários negros: uma conquista e um desafio a permanecer na posição conquistada. In: OLIVEIRA, Iolanda (org.). Cor e Magistério. Niterói: Quartet/EDUFF, 2006. p.157-183.

ZACONNE, Orlando. Indignos de vida: a forma jurídica de extermínio de inimigos na cidade do Rio de Janeiro. Rio de Janeiro: Revan, 2015. Edição digital.

ZAFFARONI, Eugénio Raul. O inimigo no Direito Penal. Rio de Janeiro: Revan, 2014.

Em busca das penas perdidas: a perda de legitimidade do sistema penal. Rio de Janeiro: Revan, 2015. 